International Journal of Instruction

e-ISSN: 1308-1470 • www.e-iji.net

Article submission code:

20191027173152

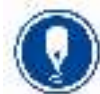

January $2021 \bullet$ Vol.14, No.1

p-ISSN: 1694-609X

pp. $65-84$

Received: $27 / 10 / 2019$

Revision: 04/06/2020
Accepted: 25/06/2020

OnlineFirst:10/10/2020

\title{
The Quality Improvement Indicators of the Curriculum at the Technical and Vocational Higher Education
}

\section{Mahboobe Mohammad Shafi}

$\mathrm{PhD}$ student of Curriculum Planning, Faculty of Education Sciences and Psychology, University of Isfahan, Iran, Mmsh.6368@yahoo.com

\section{Mohammad Reza Neyestani}

Faculty member and assistant professor of Faculty of Education Sciences and Psychology, University of Isfahan, Iran, m.neyestani@edu.ui.ac.ir

\section{Sayed Ebrahim Mirshah Jafari}

Faculty member and professor of Faculty of Education Sciences and Psychology, University of Isfahan., Iran, jafari@edu.ui.ac.ir

\section{Vida Taghvaei}

Assoc. Prof., Department of Architecture, Shariaty Technical College and Technical and Vocational University, Iran, taghvaei@ shariaty.ac.ir

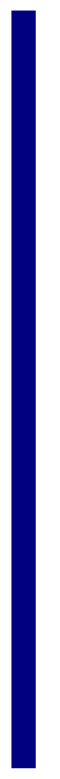

The present study seeks to develop and investigate the quality improvement indicators of the curriculum of vocational higher education in technical and vocational universities. The study employed the mixed methods research design. Two qualitative and quantitative research methods were employed for data collection. In the qualitative section, the population consisted of curriculum experts, faculty members of Iranian technical and vocational universities, and employers. In the quantitative section, the population consisted of all instructors in Shariaty Technical College in Tehran. The research data were collected through semi-structured interviewing technique and a researcher-made questionnaire. The results of qualitative research showed that in order to improve the quality of technical and vocational higher education curricula, solutions such as tailoring curricula to the professional needs of businesses, emphasizing professional standards and competencies, paying attention to focal competencies, link between employers and planners, content modulation, content applicability, work-based teaching, real-time teaching, science and practice integration, group-based and participatory teaching, performance-based assessment, student-based assessment of students' roles and tasks in learning groups, emphasis on practical work and team projects are effective on assessment. the quantitative section results indicate that the indicators obtained in the qualitative phase are valid and endorsed by the participants.

Keywords: quality improvement, curriculum, technical, vocational, higher education

Citation: Mohammad Shafi, M., Neyestani, M. R., Jafari, S. E. M., \& Taghvaei, V. (2021). The Quality Improvement Indicators of the Curriculum at the Technical and Vocational Higher Education. International Journal of Instruction, 14(1), 65-84. https://doi.org/10.29333/iji.2021.1415a 


\section{INTRODUCTION}

As one of the higher education subsystems, technical and vocational universities play a special role in the economic development and prosperity of society. Preparing the youth for job-creation skills; training skilled, competent, and entrepreneurial technicians, and interacting with industrial centers and government departments are the goals of this educational system (Monitoring, Evaluation and Quality Assurance Center, 2017). Vocational training plays a prominent role in providing people with knowledge and developing skills for employment and earnings, increase in productivity, and access to job opportunities (Nyerere, 2009; Tubsree \& Bunsang, 2013). This type of education was developed in response to societies' need for skilled labors. This meets the requirements of modern working life and partly as a result of globalization (Littke, 2015).

International conferences and forums on sustainable development have also highlighted the significance of vocational training. For example, at the Paris International Conference in 1989 and the Seoul Conference in 1999, human-centered development and its key to technical and vocational training were introduced because the development of vocational training promoted human, financial, physical, and social capital. The increase in these types of capital mat leads to sustainable political, economic, and cultural development (Mohammad Ali, 2011). In fact, vocational education is one of the effective tools for empowering individuals to achieve sustainable national development, prevention of unemployment, creation of jobs, improvement of quality of life, and promotion of a culture of peace, freedom and democracy. This view determines the goals of technical and vocational education in terms of knowledge, attitudes, work habits, and other values in learners (Olori \& Olori, 2018).

These important goals will be achieved through the high quality technical and vocational curriculum. In other words, a curriculum is one of the factors with the greatest effects on the quality of education and the achievement of the goals of technical and vocational higher education. Curricula are at the heart of educational systems and as a tool for achieving higher education goals (Rebollo \& Ivars Baidal, 2004). It is also the essence of any educational institution. It acts as a transmitter of applied information, which provides a context for the development and acquisition of skills and knowledge creation and ensures the effectiveness of the educational system (Toghani, 2012; Ghorbani et al. 2014; Bharvad, 2010).

The curriculum of technical and vocational higher education plays important roles in the success or failure of these institutions and reflect the extent to which universities respond to changing needs of society (Shams \& Ma'arefvand, 2015). Curricula also directly affect the outcomes of the education system because they provide the specialized knowledge, skills and abilities necessary for learners (Fathi Azar et al., 2012). The European Center for the Development of Vocational Education (2012) introduces the curriculum as a pillar of the entire education process and considers it a tool for achieving higher education goals. The most important element of every university is its curriculum, guaranteeing the effectiveness of its activities (Bharvad, 2010). 
Consequently, in order for technical and vocational universities to succeed in fulfilling their goals and missions, they should pay close attention to their curriculum and develop it through comprehensive studies and reviews.

But the investigation on the status of technical and vocational university shows that their goals are not fulfilled, and their curricula encountered numerous challenges and failures. Conducted researches indicate that the current technical and vocational curriculum has not been able to adequately perform the job creation and meet the technical and vocational needs of the labor market. This curriculum does not meet favorable quality. In this regard, studies such as Khanipur et al (2016), Jafari Harandi (2014), Forouzeh (2015), Navidi and Barzegar (2012), Moslemi and Mousavi (2015), Sharif et al. (2007), Salehi Omran (2004), Jafari Harandi (2003), Barzegar (2003), Attaran (2001), Akrami (2001) pointed out that these failures including the disproportionate skills of technical and vocational graduates' skills to the needs of society and the labor market, no updated training, no interaction and proportion between changing needs and training, inadequate learning time, unsatisfactory physical facilities and educational space, lack of coordination between theoretical and practical training, and ineffectiveness of technical and vocational colleges.

Moreover, despite the prominent role of curricula in the qualitative growth and achievement of academic goals and its prominent position in all needs of assessment and accreditation institutions, the degree of attention to them is insufficient and limited in monitoring and evaluation mechanisms. In fact, curricula are marginalized (Hosseini \& Nasr, 2012). While, according to Hunkins \& Ornestein (2016), curricula are at the heart of academic centers and are one of the most important tools and elements of realization of the overall goals and objectives of the higher education system. Insufficient attention to curricula and their roles can raise many issues and problems.

In the field of improving the quality of curricula in technical and vocational higher education, there has been no detailed and objective study to identify effective indicators to improve and evaluate the quality of curricula. Nasirian, Samari, and Namvar (2018) examined concepts related to factors affecting educational quality at the Technical and Vocational University.

Hassanzadeh, Yamani Doozi, Salehi Omran and Khorasani (2017) explained the factors inhibiting and promoting quality in technical and vocational higher education. They consist of two factors, namely internal and external factors. Moreover, the balance between external and internal factors can be examined. Sadri, Zahedi et al. (2017) compared the technical and vocational curriculum and the supply of the technical and vocational graduates with the demand of human resources in this sector. Finally, the results showed that in order to increase the real effectiveness of technical and vocational education in Iran, the curriculum should have some modifications tailored to the needs and requirements.

Said (2018) examined in-depth understanding of features of effective lecturers of technical and vocational education. In a study titled "Quality assurance of the qualification process in TVET: Malaysia Country", Mohd Amin (2016) identified major 
strengths and shortcomings in the current Malaysian technical and vocational system and offered some suggestions for improving the quality assurance of the system. Sermsuk et al. (2014) developed a model for the technical and vocational curriculum.

Generally speaking, the efforts made in each research and its findings have been in line with enlightening and improving technical and vocational education. Only assessing quality of technical and vocational education, the employment rate of students and the identification of issues and problems of the vocational education system have been addressed, and technical and vocational higher education has received less attention. Also, only some studies have provided guidelines for improving educational quality that can be implemented and supplemented in this research. However, quality of curricula and their elements such as goals, content, teaching and assessment in technical and vocational higher education has been neglected in previous research. The innovation of the present study is to study and identify effective indicators of improving the quality of the technical and vocational university curriculum. It is important to acknowledge the importance and necessity of this new idea and research to improve the quality of curricula. There is no consensus on the meaning of quality in higher education due to the different dimensions of the quality issue and the diversity of stakeholders' views on its nature. Quality in higher education can be defined as a flexible concept that can be adapted to the circumstances. Considering ISO, quality in higher education means the production of goods and services in accordance with the demands and standards accepted by the audience (Momeni Rad \& Ali Abadi, 2010). The International Network of Quality Assurance Institutions in Higher Education defines the quality of the academic system as being in compliance with: (a) predetermined standards; and (b) missions, goals, and expectations (Mohammadi, Zamanifar, and Sadeghi Mandi, 2015).

Therefore, given the significance of quality in global competitions and the increasing demands for improved quality of curricula in technical and vocational higher education institutions, addressing this issue is crucial. Poor quality of the curriculum in this area leads to the poor labor market and ultimately the goals of economic, social, and cultural development plans of the country will face numerous problems. Therefore, considering the significance of the issue, this research aims to study and identify the quality improvement indicators of the curriculum of technical and vocational university. By identifying these indicators, actions can be taken by technical and vocational university staff to develop and improve the quality of its curriculum.

\section{METHOD}

The present study employed an exploratory mixed methods research. For the purpose of the study, the researchers conducted in-depth interviews with curriculum specialists, employers, and faculty members of the Technical and Vocational University in order to identify the quality improvement indicators of the curriculum of technical and vocational university. Then, using quantitative method and through the opinions of lecturers at Shariaty Technical College in Tehran, the indicators (increasing the validity of the indicators) were confirmed. 
The research statistical population in the qualitative section consisted of the nationwide curriculum experts, academic members of the specialized curriculum committees of Shariaty Technical College of Tehran, as well as employers who employed graduates of technical and vocational universities. In sum, 18 individuals were selected via the purposive sampling method and interviewed as participants of this section, including 6 curriculum planners, 7 faculty members of Shariaty Technical College, and 5 employers. That is, selected individuals were prominent examples of the subject and objectives of the research and possessed valuable information (Gall, Borg, \& Gall, 2004: 389). The research population of the quantitative section consisted of all lecturers and faculty members at Shariaty Technical College in the academic year 2018-2019 (including 571 individuals). The participants of this section were estimated as 230 individuals by the Cochran formula and selected via proportionate stratified random sampling technique. The participants were lecturers and members of various faculties.

The research data were collected through semi-structured interviewing technique and a researcher-made questionnaire. The researchers conducted semi-structured interviews with the curriculum experts, employers, and faculty members of the specialized curriculum committees on the quality improvement indicators of the curriculum of vocational and technical university. The validity of the interview questions was confirmed using the content validity method. In order to assess the reliability of the interviews, four experts from the Department of Educational Sciences at University of Isfahan reviewed and approved the identified categories. The researchers used a researcher-made questionnaire to validate the quality improvement indicators of the curriculum of technical and vocational university. The validity of the questionnaire was confirmed by seven experts of quality improvement and curriculum planning. To estimate the reliability of the questionnaire, 30 copies of the questionnaire were distributed among the statistical population and its reliability coefficient was calculated as 0.86 using Cronbach's alpha.

\section{FINDINGS}

\section{Research Question 1}

What are the quality improvement indicators of the curriculum of vocational and technical university in the terms of objectives?

6 Indicators are listed in Table 1. The most important quality improvement indicators of the curriculum of technical and vocational university in terms of objectives were identified by the curriculum experts and faculty members in the specialized curriculum committees of technical and vocational universities. Along with a brief overview of the interviews, they are presented below. 
Table 1

Frequency and percentage of participants' responses regarding the quality improvement indicators of the curriculum of technical and professional university

\begin{tabular}{|c|c|c|c|}
\hline Row & Indicators & $\mathrm{F}$ & Per. \\
\hline 1 & Goal setting based on labor market needs & 18 & 100 \\
\hline 2 & $\begin{array}{l}\text { Attention to the general competencies needed for the jobs in setting } \\
\text { goals }\end{array}$ & 18 & 100 \\
\hline 3 & $\begin{array}{l}\text { Emphasis of goals on the professional standards and competencies } \\
\text { needed by jobs }\end{array}$ & 17 & 94.4 \\
\hline 4 & Goal setting based on new job opportunities & 14 & 77.7 \\
\hline 5 & $\begin{array}{l}\text { Emphasis of goals on students self-employment and } \\
\text { entrepreneurship }\end{array}$ & 13 & 72.2 \\
\hline 6 & $\begin{array}{l}\text { Employers' interaction and participation in the process of setting } \\
\text { goals }\end{array}$ & 11 & 61.1 \\
\hline
\end{tabular}

1. Goal setting based on labor market needs: This quality improvement indicator was recommended and emphasized by 18 participants $(100 \%)$. The interviewees believed that given the unparalleled role of the technical and vocational college in creating employment and training in the labor market, it is necessary to set goals tailored to the curriculum of technical and vocational university, always in line with the professional needs of jobs and the labor market. The goals of the curriculum of $t$ technical and vocational education must address the set of market and industry skills needed to meet the needs of contemporary competitive world. Goals should be set to meet the growing needs of professions, and the students should have acquired skills after graduation. It can meet the professional needs and expectations.

2. Attention to the general competencies needed for jobs in setting goals: This quality improvement indicator was highlighted by 18 participants $(100 \%)$ in the study. All interviewees believed that the technical and vocational curriculum should be capable of enhancing the competencies required for learners. They argued that employers want graduates to master a set of general skills that are transferable from one job position to another, in addition to technical skills. Graduates must have good interpersonal skills and knowledge needed to adapt quickly to new ideas and techniques, and to grow consistently. Moreover, thinking skills such as problem solving, critical thinking, creative thinking; and professional skills such as entrepreneurship and job creation; and desirable personality traits such as responsibility, hard work and management should be developed among them.

Emphasis of goals on professional standards and competencies: This indicator was recommended and emphasized by 17 participants $(94.4 \%)$. The interviewees believed that one of the issues that should be addressed in quality improvement of the technical and vocational curriculum is its ability to reduce the gap between the workforces' level of professional competences and the national and international standards. In fact, we need to see that the labor market qualifications overlap with the competencies seen in the curriculum. Providing vocational training should not only be tailored to the needs of the economy but must also be based on occupational standards and competencies. 
4. Curriculum goal setting based on new job opportunities: This indicator was recommended and emphasized by 14 participants $(77.7 \%)$. The interviewees argued that curricula are a means of addressing failures and must be based on new opportunities to achieve quality and efficiency. Given that the situation in Iran and the world has changed a lot compared to the past, we are confronted with general trends such as globalization, changing production methods, knowledge development and continuous technology changes that have created new job opportunities. As a result, the market needs human resources with new or complementary skills compatible with new job opportunities. Technical and vocational education should therefore be kept up-to-date, enabling the development of new skills and technologies that are constantly evolving and changing.

5. Emphasis of goals on students' self-employment and entrepreneurship in setting goals: This indicator was recommended and emphasized by 13 participants $(72.2 \%)$. The interviewees believed that while the main goal of the technical and vocational college is to develop efficient and specialized forces, the technical and vocational university is working through interaction with industrial centers and government departments, to provide entrepreneurship and self-employment opportunities for applicants and present a model for third-generation, entrepreneurial, and employer universities in addition to providing the necessary background for skills acquisition.

6. Employers' interaction and participation in the process of setting goals: This indicator was emphasized by 11 participants $(61.1 \%)$. The interviewees pointed out that providing employers with opportunities to specialize in technical and vocational college curriculum committees in order to determine and formulate curriculum goals will enable industry and labor market skills needs to be accurately and properly transferred to technical and vocational universities, and consequently a balance is created between technical and vocational education and industry needs. In the absence of interactions of the technical and vocational university with industry and employers, the educational content may not meet their needs and the graduates of the technical and vocational university will not be able to find a suitable job.

\section{Research question 2}

What are the quality improvement indicators in the technical and vocational curriculum in terms of content?

The 7 indicators listed in Table 2 are the most important of the quality improvement ones of the curriculum of technical and vocational university in terms of content from the perspective of curriculum experts, faculty of technical and vocational universities, and employers. Then, a brief overview of the interviews is provided. 
Table 2

Frequency and percentage of participants' responses regarding indicators of the quality improvement indicators of the curriculum of technical and professional university in terms of content

\begin{tabular}{llll}
\hline Row & Indicators & F & Percentage \\
\hline 1 & Applicability of content & 18 & 100 \\
\hline 2 & $\begin{array}{l}\text { Content revision and its updatedness along with the latest } \\
\text { professional developments and changes }\end{array}$ & 18 & 100 \\
\hline 3 & Content formulation as practical modules and workshop units & 16 & 88.8 \\
\hline 4 & Content diversity to deliver a range of skills & 15 & 83.3 \\
\hline 5 & $\begin{array}{l}\text { Localization of the content and its adaptation to the climate, } \\
\text { geography and culture of each region }\end{array}$ & 13 & 72.2 \\
\hline 6 & Focus on lifelong learning culture in content formulation & 12 & 66.6 \\
\hline
\end{tabular}

1. Applicability of content: According to all interviewees (100\%), one of the indicators of improving the quality of content of the curriculum of technical and vocational university is the applicability of the content. They believed that, given the purpose of the technical and vocational education, which is to train efficient workforces, the content of the technical and vocational curriculum should be useful in practice and be applied and relevant to students' professional lives. It should also lead to the development of skills in the business world. In fact, the curriculum content should be designed so that students understand what they are learning and what they are learning to use in the future. Also, the technical and professional curriculum content should be such that the student can apply the skills, knowledge and attitudes he or she learns in different work situations.

2. Content revision and updatedness along with the latest professional developments: This indicator was highlighted by 18 participants (100\%). The interviewees argued that changes in the business world due to the emergence of new technologies make educational standards and curriculum content invalid and inefficient. In order to avoid this fact and maintain the quality of curricula, national standards of education and content should be designed so that it can be easily updated through a needs analysis system. According to the interviewees, technical and vocational education should be up to date to meet the new and growing needs of professions and businesses.

3. Content formulation as practical modules and workshop units: This indicator was recommended and emphasized by 16 participants (88.8\%). According to the interviewees, given the purpose of the Technical and Vocational University which seeks to prepare its learners to enter the industry, the curriculum content should be a guide to action and be formulated and practiced. Practical modules and laboratory units are important components of development programs and especially economic development, which can play an important role in empowering people and enhancing innovative capabilities in achieving high quality curriculum.

4. Content diversity to deliver a range of skills: This indicator was confirmed by 15 participants $(83.3 \%)$. The interviewees pointed out that in order to improve the curriculum quality of technical and vocational university, the importance of multifaceted 
programs should be taken into account. They believed that one of the most important characteristics of technical and vocational curricula is the flexibility and ability to respond to changing needs. Content should not just focus on one thing or one type, but on different aspects of needs. Moreover, contemporary societies need people who are familiar with a wide range of skills to respond to changes rather than those having a limited domain. Professional and technical curriculum needs to acquire extensive knowledge and basic skills which are applicable to a number of occupations within a discipline, so that the individuals, with specific training, are not restricted to the appointment of occupation, and their transference from one occupation to another can be facilitated during his lifetime.

5. Localization of the content and its adaptation to the climate, geography, and culture of each region: This indicator was recommended and confirmed by 13 participants $(72.2 \%)$. The interviewees believed that the content taught at the Technical and Vocational University should be tailored to the different climates and geographies of Iran because Iran has many different climates, and each climate requires its own curriculum. Therefore, the curriculum should be able to take into account climate characteristics and differences. For example, in the field of climate engineering Yazd city has its own architecture and the north of Iran requires another type of architecture. Therefore, professional and technical curricula pay attention to these needs.

6. Focus on lifelong learning culture in content formulation: This indicator was recommended and confirmed by 12 participants $(66.6 \%)$. The interviewees believed that lifelong learning provides the opportunity to update knowledge and resume practical abilities and skills in the personal context. It also empowers individuals to adapt to technological changes in their jobs or to try another profession. The overriding goal of lifelong learning is to teach a learner how to learn. They believed also that lifelong learning is an integral part of the vocational system. To support lifelong learning, technical and vocational systems must be open, flexible and inclusive. They should do more than equip students with the specific knowledge and skills of a job.

\section{Research Question 3}

What are the quality improvement indicators of the curriculum of technical and vocational university in the terms of teaching methods?

The 5 indicators listed in Table 3 are the most important of quality improvement indicators of the curriculum of technical and vocational university in terms of teaching strategies from the perspective of curriculum experts, faculty members of technical and vocational universities, and employers. They are further discussed, and brief excerpts of the interviews are provided. 
Table 3

Frequency and percentage of participants' responses regarding indicators of the quality improvement indicators of the curriculum of technical and professional university in terms of teaching strategies

\begin{tabular}{llll}
\hline Row & Indicators & $\mathrm{F}$ & Percentage \\
\hline 1 & Using work-based teaching strategies and empirical activity & 18 & 100 \\
\hline 2 & $\begin{array}{l}\text { Integrating science and practice in teaching (illustrating how } \\
\text { theoretical knowledge is applied in practice) }\end{array}$ & 18 & 100 \\
\hline 3 & $\begin{array}{l}\text { Teaching in real work environments or simulated environments } \\
\text { such as labs and workshops }\end{array}$ & 17 & 94.4 \\
\hline 4 & $\begin{array}{l}\text { Employing expert workshop and laboratory technicians to teach } \\
\text { practical units }\end{array}$ & 12 & 66.6 \\
\hline 5 & Using group-based and participatory learning & 12 & 66.6 \\
\hline
\end{tabular}

1. Using work-based teaching strategies and empirical activity: This indicator was confirmed by 18 participants $(100 \%)$. The qualitative findings of the interviews show that the best type of training at this university is skill-based training, given that the students seek to learn skills and work in practice. According to the interviewees, educators should avoid transferring mere theories to the students, but they should provide an environment for experimentation by the trainees themselves in the labs and workshops, and students should be able to experience their theoretical approaches and lessons learned in practical situations. In addition, students should practice their theoretical approaches and lessons learned in practical situations and analyze their own experiences.

2. Integrating science and practice in teaching: This indicator was recommended and emphasized by 18 participants $(100 \%)$. The interviewees believed that theoretical knowledge should be combined with practical work to enable trainees to master the necessary skills and professional training for graduates. They argued that teachers should communicate between theoretical and practical topics and present the theory and practice of knowledge in harmony and coherence with students, and put them into practice in the classroom when teaching theoretical topics. What the students learn at the technical and vocational university should be explained in real work environments or laboratories with practical applications. They pointed out that the technical and vocational curriculum should form a totality based on the integration of theory and practice, presented in a way that motivates learners.

3. Teaching in real work environments or simulated environments such as labs and workshops: this indicator was confirmed by 17 participants $(94.4 \%)$. According to the interviewees, in order to prepare students for effective work and presence in the labor market, it is better to teach in the real work environment in order to get closer to the job and integrate with the real world of work. In addition, the high cost of many technical and vocational disciplines should be taken into consideration and more attention should be paid to learning in the workplace in order to reduce costs. Also where it is not possible to provide students with direct practical experience due to the lack of conditions to create a realistic environment, the university's task is to provide a 
simulated location such as a lab and workshops, which should, as far as possible, looks like real world situations, both in appearance and equipment.

4. Employing expert workshop and laboratory technicians to teach practical units: This indicator was recommended and emphasized by 12 participants (66.6\%). According to the interviewees, professors play an important role in achieving the curriculum goals. Accordingly, given that technical and vocational students are expected to work in the industry, it is essential that instructors be selected, especially to teach practical courses, from qualified and experienced individuals with a professional background and knowledge of labor market needs. When a person enters a technical and vocational university without a work experience, his or her methods and abilities will become complete day by day because he/she is not familiar with the new technology of the profession and the job market. We need professors who have mastered the work and practical skills, have worked in the field for years, have learned the skills, have the experience and are going to transfer this experience to the students.

5. Using group-based and participatory learning: This indicator was confirmed by 12 participants $(66.6 \%)$. As the interviewees believed, considering the practical aspects of the vocational and technical curriculum compared to other higher education subsystems, it is necessary to pay more attention to the participatory and group teaching aspects so that the students have the necessary skills and earn teamwork in their professional future. This will not happen unless the teaching and training of learners is based on this thought.

\section{Research Question 4}

What are the quality improvement indicators of the curriculum in technical and vocational university in terms of assessment?

The 6 indicators listed in Table 4 are the most important of quality improvement indicators of the curriculum of technical and vocational university in the terms of assessment from the perspective of curriculum experts, faculty members of technical and vocational universities, and employers.

Table 4

Frequency and percentage of participants' responses regarding indicators of the quality improvement indicators of the curriculum of technical and professional university in terms of assessment

\begin{tabular}{llll}
\hline Row & Indicators & F & Percentage \\
\hline 1 & Student learning assessment based on performance tests & 18 & 100 \\
\hline 2 & Presentation of periodic feedbacks to correct student performance & 16 & 88.8 \\
\hline 3 & Emphasis on practical work and team projects in assessment & 16 & 88.8 \\
\hline 4 & $\begin{array}{l}\text { Learning assessment by survey of relevant agents of } \\
\text { apprenticeship environment }\end{array}$ & 13 & 72.2 \\
\hline 5 & Student learning assessment based on all educational goals & 12 & 66.6 \\
\hline 6 & Assessment by a survey of student's teammates & 10 & 55.5 \\
\hline
\end{tabular}


1. Student learning assessment based on performance tests: This indicator was confirmed by 18 participants (100\%). The interviewees believed that the method chosen for the assessment of the technical and professional curriculum should be commensurate with the goals, content, and teaching strategies of the university. Given that a number of skills and competencies are being taught at this university, the assessment should be based on the ability to do the job and the assessments should be designed and planned to measure the ability to do the job. Paper pencil tests are certainly not suitable for measuring skills, but rather, appropriate practice tests should be designed to measure skills.

2. Presentation of periodic feedbacks to correct student performance: This indicator was confirmed by 16 participants (88.8\%). The interviewees believed that assessment of students' performance should be such as to inform them of the strengths and weaknesses of their performance. They believed also that assessment should have a feedback system in order to identify learning problems and their causes and some steps should be taken to eliminate them. Presentation of periodic feedbacks to correct students' performance allows them to take responsibility for their own work while observing their own performance feedback and to use others' experiences in addition to learning from their own experiences.

3. Emphasis on practical work and team projects in assessment: This indicator was confirmed by 16 participants $(88.8 \%)$. According to the interviewees, the emphasis on practical work and group projects in assessments enables the evaluation process to be multi-faceted, not just measuring cognitive skills, but also emphasizing learners' abilities in a variety of areas, both practical and group skills. They believed that practical and group activities designated as projects and assignments in case of assessment enhance students' social engagement and interactions as well as create a sense of interdependence and influence among them. These activities teach them to work together and exchange information for accomplishment of projects. These interactions may build empathy, trust and shared knowledge.

4. Learning assessment by survey of relevant agents of apprenticeship environment: This indicator was recommended and emphasized by 13 participants $(72.2 \%)$. Interviewees argued that one of the methods that can be used to measure students' skills is the survey of employers and technicians supervised and guided by students during their apprenticeship. Due to their close interactions with the student in the workplaces, employers and technicians can give best comment on students' abilities. Interviewees also believed that surveys of relevant agents in an apprenticeship will have beneficial results, as both the apprenticeship reflects the students' actual and future work environment and feedbacks on the student from relevant agents improve their performance.

5. Student learning assessment based on all educational goals: This indicator was recommended and emphasized by 12 participants $(66.6 \%)$. Although the primary goal of technical and vocational university is skill training, it must always be kept in mind that this will not be the case unless other goals are met and measured in assessments. According to the interviewees, any effective learning requires the development of 
different skills. It will not be facilitated unless they provide feedbacks and measure goals in different contexts.

6. Assessment by a survey of student's teammates: This indicator was recommended and emphasized by 10 participants $(55.5 \%)$. They believed that most of the teachinglearning activities in technical and vocational education are carried out in groups. Assessment should be done in the sections where students are working as a group, as teammates are the best individuals who are aware of their peers' actual performance. Assessments done by teammates' surveys reflect their opinions about a students' performance. These surveys can be received in written and oral form. They are actually the teammates' cognitive, meta-cognitive, and emotional judgments. Students receive information about their progress and positions. This information may help them improve their performance.

\section{Research Question 5}

How valid are the quality improvement indicators of the curriculum of technical and vocational university?

Table 5

Comparison of mean scores of quality improvement indicators of the curriculum of technical and vocational university with hypothetical mean value 3

\begin{tabular}{lllllll}
\hline Component & Mean & SD & Mean deviation & T & df & Sig. \\
\hline Goals & 4.43 & 0.48 & 0.032 & 44.684 & 229 & 0.001 \\
\hline Content & 4.33 & 0.41 & 0.027 & 48.993 & 229 & 0.001 \\
\hline Teaching strategies & 4.38 & 0.49 & 0.032 & 42.463 & 229 & 0.001 \\
\hline Assessment & 4.33 & 0.48 & 0.032 & 41.585 & 229 & 0.001 \\
\hline
\end{tabular}

From Table (5), the mean scores of quality improvement indicators of the curriculum technical and vocational university in terms of goals is 4.43 , in terms of content is 4.33 , in terms of teaching strategies is 4.38 , and in terms of assessment is 4.33 . Since the tobserved for each of these components is bigger than the t-table; therefore, the validity of these indicators is higher than the average level of quality improvement of the curriculum of technical and vocational university, that is to say that these indicators have been approved as those effective on quality improvement of the curriculum of technical and vocational university by its lecturers and faculty members.

\section{DISCUSSION}

Given the effect of technical and vocational higher education on employment and entrepreneurship and its role in providing human capital and on the other hand, numerous failures and problems of this system, including lack of satisfactory technical and vocational education skills, no compatibility with the needs of the labor market, no appropriate teaching methods, and the gap between the level of education and the needs of the industry highlight the significance of the quality improvement of curriculum at technical and vocational university. In order to improve the quality of technical and vocational higher education, it is necessary to improve the quality of its curriculum in terms of essential factors of achieving the goals of technical and vocational higher 
education. The present study aimed to identify the effectiveness of the quality improvement indicators of curriculum in the terms of goals, content, teaching strategies, and assessment.

From the interviewees' perspectives, factors affecting quality improvement of the curriculum in terms of goals include setting goals based on labor market needs, paying attention to the general competencies needed for the jobs in setting goals, emphasizing goals on the professional standards and competencies needed by jobs, setting goals based on new job opportunities, emplacing goals on students' self-employment and entrepreneurship, and employers' interaction and participation in the process of setting goals. The results are consistent with the results of the previous studies such as Nasirian et al. (2018), Sadri et al. (2017), Fix Lax et al. (2015), Rashidi (2013), Idris \& Mumbai (2017), Bazargan (2015). ), Forouzesh et al. (2015), Mohammadi and Zamanifar (2016), Salehi Omran and Ghasemzadeh (2013), Amini et al. (2012), and Khanipour et al. (2016). Have pointed to the need of the market. Hosseini and Nasr (2012), Sadri et al. (2017), Hassanzadeh et al. (2017) have emphasized the relationship between education and industry and the involvement of stakeholders and employers in the process of setting the goals.

One of the most important goals of technical and vocational higher education is the training of efficient human resources. The condition for the realization of this goal is the relevance between the objectives of the technical and vocational curriculum and the labor market. Accordingly, due to employers' knowledge of the skills and specialties required by the labor market, technical and vocational university can recognize the needs of businesses and responds to their demands. Another factor that contributes to improving the quality of technical and vocational curriculum is the focus on entrepreneurship and job creation. It makes technical and vocational students more risktaking and always looking for new ways to solve problems and create new opportunities for employment. Aligning goals with new job opportunities is also effective on improving the quality of curricula.

Investigating the interviewees' perspectives revealed that applicability of content, Content revision and its updatedness along with the latest professional developments and changes, content formulation as practical modules and workshop units, content diversity to deliver a range of skills, localization of the content and its adaptation to the climate, geography and culture of each region, focus on lifelong learning culture in content formulation, and integration of knowledge, attitudes and skills into curriculum content are the most important quality improvement indicators of the curriculum of technical and vocational university. The results of this part of the research are consistent with those of Nasirian et al. (2018), Sadri et al. (2017), Amini et al. (2012), Motahharinezhad (2012), Tsinidou et al. (2010) regarding the content formulation in a practical and applied method. These researchers consider the content quality of educational programs to be a factor in improving the quality of the curriculum of technical and vocational education.

Students need to be exposed to content enhancing their ability to apply what they have learned in the real work environment and even to create or find the right job. Students 
need to understand the content of what they are learning in the future, so that they can easily apply their skills in the workplaces and undertake assigned tasks after graduation. Moreover, content should contain updated professional knowledge. While using the most up-to-date global information and knowledge of the profession, instructors should be innovative and localize knowledge in the specific conditions of each area, rather than merely copying and imitating it. Content should be a guide to students' practice, so that they can learn the skills step by step. Also, content should equip learners with a set of skills and focus on different aspects of the needs so that if a technician's job opportunity is lost, he or she can apply for another job. In addition, the content of the technical and vocational curriculum should be comprehensive, and training should provide a learning space for doing activities with one another.

As findings of the indicator of teaching strategies showed, the interviewees believed that using work-based teaching strategies and empirical activity, integration of science and practice in teaching, teaching in real work environments or simulated environments such as labs and workshops, employing expert workshop and laboratory technicians to teach practical units, and using group-based and participatory learning are the most important factors in improving the quality of curriculum in terms of teaching.

The results in this research section are consistent with the findings of Fix Lax et al. (2015), Nasirian et al. (2018), Amani et al. (2015), Mohd Amin (2016), Hook (2016), Rashidi (2013), Idris and Mbudai (2017), Amani et al. (2015), and Nazari Noghabiet et al. (2010) regarding teaching with an empirical and practical approach as one of the factors affecting the quality of the curriculum of technical and vocational education. According to the research findings, the quality improvement of vocational college education depends to a large extent on the use of practical teaching and the methods that lead to learning through acting. In fact, educators should communicate between theoretical and practical topics, present theoretical and practical knowledge in a coherent and harmonious manner to the trainees and put them into practice when teaching theoretical topics in the classroom.

As the research results showed, the professors' and lecturers' work experience are very effective on improving the quality of education. Their direct communication and interaction of with the profession and their presence in the industry will lead to real experiences tailored to the needs of the labor market, as well as up-to-date professional knowledge tailored to the latest career changes and developments. An empirically trained and untrained lecturer is not able to accommodate students with today's rapidly changing technology and changing needs of the labor market. Using group and participatory approaches in teaching was also emphasized in the research. Instead of individual training, the education systems should emphasize group training, and students should be encouraged to work together and learn.

Finally, in relation to the fourth research question, from the interviewees' viewpoints, using performance tests, periodic feedbacks, emphasis on practical work and group projects, survey of relevant agents of apprenticeship environment for assessment based on all educational goals, continuous assessment and peer-to-peer assessment were the most important indicators of quality improvement in terms of curriculum assessment. 
The results of this section are consistent with the research findings of Sheikholeslami (2013) and Amini et al. (2012), emphasizing the significance of student work groups and continuous assessment of learners' performance.

Using performance tests is important because of their ability to assess students' professional skills and competencies in technical and vocational education. Another important factor is providing opportunities for students to provide appropriate periodic feedbacks through which students become aware of their performance strengths and weaknesses and find out how far they have come to achieve the desired status and skill level. Assessments also need to be designed to prepare students for the world of work and to learn the skills necessary for their personal and professional lives. Assessments should also be comprehensive and meet all the objectives. Given these results, it is essential that curriculum planners and practitioners consider vocational higher education to improve the quality of extracted syndrome curricula and use them in curriculum designing and planning. Improving the quality of education at technical and vocational university requires consideration of all the factors identified in this study.

\section{CONCLUSION}

Improving the quality of education at technical and vocational university requires consideration of the factors identified in this study. Accordingly, it is that essentially:

- In the process of curriculum planning, to identify the needs of the labor market, a deep linkage between technical and vocational higher education planners with industry employers, between intended goals and content, and expected general and professional skills should be made. The labor market needs coordination.

- Revising traditional teaching methods and application of practical teaching approaches in technical and vocational higher education as well as proper utilization of space, facilities and equipment of factories and industries to teach practical lessons.

- Revising and updating the curriculum content of technical and vocational university and tailoring it to new job opportunities in order to benefit the professional and public competencies required by the jobs.

- Focusing on learning in the workplaces and providing the opportunity for students to attend industrial centers and factories to prepare students for a more effective presence in the labor market and closer to jobs.

\section{REFERENCES}

Akrami, H. (2001). Assessing external performance of vocational technical and vocational high schools in Golestan Province, Graduates 1997 to 1999. Research Report of Golestan Province Education Organization.

Amani, A. R., Kamai, A., Nuri, N., \& Vandi, A. (2015). Factors influencing the quality of technical and vocational training from the viewpoints of students of Ahvaz agricultural school. Journal of Agricultural Education Management Research, 33, 1526. 
Amini, M. Ganji, M. Yazdkhasti, A. (2012). Assessing the quality of engineering curricula from the students' point of view (Case study: Kashan University). Iranian Journal of Engineering Education, 14(55), 61-87.

Attaran, N. (2001). Investigation of employment status and employment related factors of graduates of its branch in Mashhad. Khorasan General Education Office.

Barzegar, M. (2003). Study of employment status of building planning and accounting skills learners in Tehran City. Research project of Tehran Education Organization.

Bazargan, A. (2015). Educational evaluation. Tehran: SAMT.

Bharvad, A. J. (2010). Curriculum evaluation. International Research Journal, 1(12), 72-74.

European centre for the development of vocational training (Cedefop) (2012). Curriculum reform in Europe. The impact of learning outcomes. Luxembourg: Publications Office of the European Union. Available at: www.cedefop.europa.eu/files/5529_en.pdf.

Fathi Azar, E. Badri Gargari, R., \& Ghahremanzadeh, F. (2012). Assessing the quality of educational technology curriculum. Journal of Educational Measurement and Evaluation Studies, 1(1), 9-31.

Forouzesh, A., Karimi. M., Amini, A., \& Khanjari, S. (2015). Evaluation of quality of market-based skills training in Isfahan general technical and vocational training department based on SERVQUAL Model. Quarterly Journal of Learning, 3(11), 99-110.

Gall, M., Borg, W. \& and Gall, J. (2004). Quantitative and qualitative research methods in educational sciences and psychology. Ahmad Reza Nasr et al. (Trans.). Tehran: SAMT.

Ghorbani, S. Nili, M. R. \& Delbari, S. (2014). Comparative study of higher education curriculum assessment. Journal of Higher Education Curriculum Studies, 5(9), 90-106.

Hassanzadeh Barani Kord, S., Yamani Dozi Sarkhabi, M., Salehi Omran, E., \& Khorasani, A. (2017). Explaining the factors inhibiting and promoting quality in engineering technical higher education (case study: faculty of engineering and state universities of Tehran. Journal of Department of Educational Sciences, Shahid Chamran University, 24(1), 179-202.

Hoque, A. E. (2016). Quality assurance as a way to support labour markets: a reflection on TVET policies in Bangladesh. TVET@ Asia, (7), 1-17.

Hosseini, M. \& Nasr, A. R. (2012). Validation of higher education in the third millennium with curriculum focus. Journal of Higher Education Letter, 5(17), 13-48.

Hunkins, F. P., \& Ornstein, A. C. (2016). Curriculum: Foundations, principles, and issues. Pearson Education.

Idris, A., \& Mbudai, Y. (2017). Technical and Vocational Education: Challenges Towards Youths Empowerment in Kano State-Nigeria. Journal of Technical Education and Training, 9(1), 1-12. 
Jafari Harandi, Reza. (2014). Evaluation of External Performance of Technical and Vocational University. Journal of Educational Measurement and Evaluation Studies, 5(9), 173-198.

Jafari Harandi, R. (2003). External performance evaluation of technical and vocational technical schools of Isfahan province in the fields of electrical, automotive mechanics, manufacturing, design and sewing and accounting during the years 1998, 1999, and 2000. Isfahan: Provincial Education Research Council.

Khanipour, O., Tajoddin, A., Akhlaqi, S. M. F., Zirak Abdarloo, A., \& Navidi, M. A. (2016). Technical and vocational education system in educational skills, employment and sustainable development. The 5th National Conference and the Fourth International Conference on Skills and Employment. Tehran. Iranian Technical and Professional Organization.

Littke, K., \& Thång, P. O. (2015). Learning at work in higher vocational education. Nordic Journal of Vocational Education and Training, 5(1), 1-17.

Ministry of Science Monitoring, Evaluation and Quality Assurance Department. (2017). Reports on Strategic Analysis and Evaluation of Higher Education Subsystems.

Mohammad Ali, M. (2011). Vocational training and ways to improve it. Quarterly Journal of Development of Vocational Education and Work and Knowledge, 7(1), 1018.

Mohammadi, R., Zamanifar, M., Sadeghimandi, F. (2015). Assessing the status of quality assessment in applied education. Journal of Higher Education Letter, 8(30), 121151.

Mohd Amin, J. B. (2016). Quality assurance of the qualification process in TVET: Malaysia Country, $7, \quad 1-12$. Online: http://www.tvetonline.asia/issue7/mohdamin_tvet7.pdf (retrieved 11.11.2016).

Momeni Rad, A., \& Aliabadi, Kh. (2010). Quality assurance in e-learning using elearning standards. Journal of Training Strategies, 3(3), 87-92.

Motaharinejad, H., Yaghoubi, M., Davami, P. (2012). Key needs in developing Iranian engineering education strategies (section two: comparing the views of industry managers and faculty members). Iranian Journal of Engineering Education, 14(55). 1-19.

Moslemi, N., \& Mousavi, A. (2015). Evaluating the quality of curriculum planning from the perspective of training professionals of the national technical and vocational education organization (case study: professional electricians and construction electricians). Quarterly Journal of Learning, 4(14), 57-68.

Nasirian Samarain, K., Samari, I., \& Namvar, Y. (2018). Content analysis of articles in the quality of higher education: to identify the quality improvement indicators of the curriculum of technical and vocational university. Journal of Engineering Education, 20(77), 33-67.

Navidi, A., \& Barzegar, M. (2012). Assessment of technical and vocational training courses. Journal of Educational Innovations, 11(42), 161-186. 
Nazari Noghabi, S., Sha'banali Fami, H., \& Irvani, H. (2010). Factors affecting students' satisfaction with practical agricultural training. Iranian Journal of Agricultural Economics and Development Research, 43(2), 271-279.

Nyerere, J. (2009). Technical and Vocational Education and Training (TVET) sector mapping in Kenya. Amersfoort: Edukans Foundation.

Olori, Gloria I. \& Olori, Christian N. (2018). Strategies and Challenges for Empowering Youth through Technical Vocational Education and Training Programme in Rivers Stat: Benchmark Journals, 6(1), 121-131.theory: Sociology Press.

PhusaluxJ, U. B. and Fongsuwan, W. (2015). Determinants of modern management of private vocational colleges: A Structural Equation Model, Research Journal of Business Management, 9(2), 378-390.

Rashidi, R. (2013). Evaluation of collaboration between public training institutions and private industries and its importance in improving the quality of training delivery in TVET in Malaysia. 1-17. Online: http://www.tvet-online.asia/issue1/rashidi_tvet1.pdf (retrieved 30.5.2013).

Rebollo, F. V. \& Ivars Baidal, J. A. (2004). Sustainability indicators in Spanish tourism, Policy, University of Alicante.

Sadri, A., Zahedi, E., \& Rahmani, N. (2017). Quantitative growth of technical and professional graduates in Iran and demand for skilled workforces to revise the curriculum. Journal of Educational Technology, 12(2), 87-97.

Said, A. (2018). Vocational teaching-learning through the eyes of undergraduate vocational students in Malta: A qualitative exploratory study. International Journal for Research in Vocational Education and Training (IJRVET), 5(1), 42-63.

Salehi Omran, E. (2004). Investigating Factors Affecting the Career of Technical and Vocational Training. Journal of Humanities and Social Sciences, 4(12), 116-87.

Salehi Omran, E., \& Ghasemzadeh, A. (2013). Investigating general skills related to the qualification of technical and vocational education from the perspective of stakeholders. Journal of Innovation and Value Creation, 2(4). 41-24.

Sermsuk, S., Chianchana, C., \& Stirayakorn, P. (2014). A study of model of vocational curriculum development under vocational education commission using cross-impact analysis. Procedia-Social and Behavioral Sciences, 116, 1896-1901.

Shams Murkani, G. R. Ma'arefvand, Zahra. (2015). A model for guaranteeing the quality of the postgraduate educational management course. Journal of Educational Measurement and Evaluation Studies, 5(12), 95-120.

Sharif, M., Nikkhah, M., \& Nili, M. R. (2007). External performance of technical and vocational secondary education in Shahrekord based on two employment indicators and graduate education. Journal of Behavioral Research, 14(27), 55-66.

Sheikholeslami, S., Dolatabadi, S., \& Shirmohammadi, M. N. (2013). Evaluation of technical and vocational education using strategic factor analysis (SWOT) approach: a case study of Kurdistan province. Quarterly Journal of Learning, 2(6), 59-73. 
Toghiani, A. (2012). Curriculum assessment of the course of Islamic thought. Master thesis. Islamic Azad University, Khorasgan Branch.

Tsinidou, M., Vassilis, G and Panos, F. (2010). Evaluation of the factors that determine quality in higher education: an empirical study. Quality Assurance in Education, 18(3), 227-244

Tubsree, C., \& Bunsong, S. (2013). Curriculum Development of Vocational Teacher Education within the Context of ASEAN Integration Process. China: Regional Cooperation Platform for Vocational Teacher Education in Asia (RCP). 